\title{
Urinary Arginine Vasopressin: Pattern of Excretion in the Neonatal Period ${ }^{1}$
}

\author{
SUVIPA WIRIYATHIAN, CHARLES R. ROSENFELD, BILLY S. ARANT, JR., JOHN C. PORTER, \\ DANIEL J. FAUCHER, AND WILLIAM D. ENGLE \\ Departments of Pediatrics and Obstetrics and Gynecology, The University of Texas Health Science Center at \\ Dallas, Southwestern Medical School, Dallas, Texas 75235
}

\begin{abstract}
The pattern of arginine vasopressin (AVP) secretion in the immediate neonatal period is unclear. Plasma concentrations of AVP are reflected by its urinary excretion, thus providing a noninvasive method for studying the pattern of AVP release in the neonate. In these studies, we determined the pattern of urinary AVP excretion $(\mu \mathrm{U} /$ mg creatinine) during the first $2-4$ days after birth in 78 neonates, 53 of whom had various prenatal and/or neonatal complications. In well term $(n=12)$ and preterm $(n=13)$ infants mean urinary AVP excretion decreased gradually during the first 24-36 h after birth. Although term and preterm infants with perinatal asphyxia had highest initial levels of urinary AVP $(>200 \mu \mathrm{U} / \mathrm{mg}$ creatinine) and a significant negative correlation with the 1-min Apgar score was obtained, their pattern of excretion was similar to respective controls. After delivery, elevated values for urinary AVP excretion were found among infants with neonatal courses complicated by intracranial hemorrhage, hypoxic encephalopathy, and pneumothorax. Urine osmolality did not correlate linearly with urinary AVP levels, but rather attained a maximum value of $\sim 400 \mathrm{mosmol} / \mathrm{kg}$ at urinary AVP levels $<200 \mu \mathrm{U} / \mathrm{mg}$ creatinine and then plateaued. It is concluded that the decrease in urinary AVP excretion observed soon after birth generally reflects diminution of the hypersecretion of $\mathrm{AVP}$ during parturition; neonates with evidence of intrapartum asphyxia initially have increased urinary AVP excretion; however, the pattern of excretion is similar to normal infants. During the neonatal period insults such as pneumothorax and intracranial hemorrhage may cause hypersecretion of this hormone. (Pediatr Res 20: 103-108, 1986)
\end{abstract}

\section{Abbreviations}

AVP, arginine vasopressin

HMD, hyaline membrane disease

$\mathrm{Cr}$, creatinine

PV-IVH, periventricular-intraventricular hemorrhage

Investigations of AVP, or antidiuretic hormone, during the perinatal period have been focused on both its renal and extrarenal actions. Although its potent pressor effect may be more important than its antidiuretic action during this period of adaptation (1), these and other physiologic roles for AVP remain

Received November 26. 1984: accepted September 12, 1985.

Address all correspondence to William D. Engle. M.D.. Department of Pediatries, 5323 Harrv Hines Boulevard, Dallas. TX 75235.

This study was supported by funds provided by The Dallas Crystal Charity Ball. Presented in part at the 63rd Annual Meeting of The Endocrine Society. Cincinnati. OH. 1981. speculative. Umbilical cord plasma AVP levels are markedly elevated in infants with evidence of fetal distress and in those delivered per vagina when compared to delivery by cesarean section $(2,3)$. In normal infants, urine and plasma AVP concentrations have been reported to fall within $24-48 \mathrm{~h}$ following birth (3-5); however, following delivery of the high-risk neonate, the pattern of AVP secretion, reflected by either plasma concentrations or urinary excretion, has been described only in individual infants (6).

Elevated plasma AVP concentrations have been reported in newborn infants with hypoxic-ischemic encephalopathy, and urinary AVP excretion is increased in infants with severe HMD and pneumothorax (7-9). Furthermore, the syndrome of inappropriate antidiuretic hormone secretion has been described in several clinical disorders in the neonate, e.g. intracranial hemorrhage, meninitis, pneumonia, and atelectasis (10). It is unclear, however, whether AVP secretion is increased prior to or in response to these insults.

In the adult dog, up to $50 \%$ of the clearance of AVP occurs through the kidney (11) and the urinary clearance of AVP is approximately $80 \%$ of glomerular filtration rate (12). Furthermore, a strong linear correlation between plasma levels and urinary excretion of AVP has been reported for the adult dog (13), fetal and neonatal sheep (14), and human neonate $(5,9$, 15). Finally, since AVP secretion may be episodic (16) and plasma concentrations thus may rapidly change, measurement of urinary excretion of AVP may provide a more accurate estimation of integrated AVP secretion. In the infant, urine is easily collected and, importantly, it is obtained by noninvasive techniques. In the present report we measured AVP, $\mathrm{Cr}$, and osmolality in serial urine samples obtained during the first 2-4 days of life from well infants and groups of infants with specific neonatal and perinatal complications, describing for the first time a comparison of their patterns of urinary AVP excretion.

\section{MATERIALS AND METHODS}

The study population (Table 1) consists of 78 infants born at Parkland Memorial Hospital between July 1980 and April 1982 who were studied during the $1 \mathrm{st}$ wk of life. The control group was comprised of 13 preterm and 12 term infants who had no evidence of intrauterine growth abnormalities, meconium stained amniotic fluid, asphyxia neonatorum (Apgar scores $<6$ at 1 or $5 \mathrm{~min}$ ), respiratory distress, or any other complications during the 1st wk after birth. Informed consent was obtained for these urine collections. Forty-six high-risk infants with specific illnesses also were studied (groups 2 through 5, Table 1). Each of these infants required admission to the intensive care nursery; enrollment into the study required a diagnosis of meconiuin stained amniotic fluid, asphyxia neonatorum (evidenced by an Apgar score of $<6$ at 1 or $5 \mathrm{~min}$ and the need for resuscitation in the delivery room), or development of HMD soon after birth. 
Table 1. Description of infants studied (mean $\pm S D)^{*}$

\begin{tabular}{|c|c|c|c|c|c|c|c|c|c|c|}
\hline \multirow[b]{2}{*}{ Group } & \multirow[b]{2}{*}{$n$} & \multirow{2}{*}{$\begin{array}{l}\text { Birth wt } \\
\text { (g) }\end{array}$} & \multirow[b]{2}{*}{ EGA (wk) } & \multicolumn{2}{|c|}{$\begin{array}{l}\text { Mode of } \\
\text { delivery }\end{array}$} & \multicolumn{2}{|c|}{ Sex } & \multicolumn{2}{|c|}{ Apgar scores } & \multirow{2}{*}{$\begin{array}{l}\text { Mechanical ventilation } \\
\qquad(n)\end{array}$} \\
\hline & & & & $\mathrm{V}$ & $\mathrm{C} / \mathrm{S}$ & $\mathrm{M}$ & $\mathrm{F}$ & $1 \min$ & $5 \mathrm{~min}$ & \\
\hline \multicolumn{11}{|l|}{ 1. Control } \\
\hline a. Term & 12 & $3218 \pm 521$ & $39.7 \pm 0.7$ & 10 & 2 & 8 & 4 & $8.8 \pm 0.5$ & $9.0 \pm 0.0$ & \\
\hline b. Preterm & 13 & $1974 \pm 449$ & $34.5 \pm 1.6$ & 10 & 3 & 10 & 3 & $8.2 \pm 0.8$ & $8.8 \pm 0.6$ & \\
\hline 2. MSAF/asphyxia & 11 & $3118 \pm 529$ & $41.0 \pm 2.3$ & 2 & 9 & 7 & 4 & $2.2 \pm 1.5$ & $4.7 \pm 2.6$ & 6 \\
\hline 4. Pretcrm/asphyxia no HMD & 13 & $1415 \pm 491$ & $30.8 \pm 3.1$ & 8 & 5 & 4 & 9 & $2.9 \pm 1.6$ & $5.5 \pm 2.3$ & 11 \\
\hline 5. Preterm/HMD/S & 16 & $1386 \pm 455$ & $31.3 \pm 2.9$ & 7 & 9 & 11 & 5 & $5.5 \pm 2.8$ & $6.4 \pm 2.7$ & 16 \\
\hline 6. Preterm/HMD/NS & 7 & $919 \pm 326$ & $28.2 \pm 1.8$ & 2 & 5 & 5 & 2 & $4.3 \pm 2.7$ & $6.7 \pm 1.6$ & 7 \\
\hline
\end{tabular}

* EGA, estimated gestational age; $\mathrm{V}$, vaginal; $\mathrm{C} / \mathrm{S}$, cesarean section; MSAF, meconium stained amniotic fluid; $\mathrm{S}$, survivor; NS, nonsurvivor.

The diagnosis of HMD was determined by the presence of respiratory distress, a requirement of more than $40 \%$ inspired oxygen, and radiographic criteria consistent with the diagnosis (17). In an additional group of seven preterm infants (group 6), a diagnosis of HMD was determined using the same criteria; however, all of these infants expired, and most had a course complicated by pneumothorax, PV-IVH, and/or hypoxic-ischemic encephalopathy. The diagnosis of PV-IVH was made by clinical signs, lumbar puncture, computerized-axial tomography, and/or autopsy.

The well term infants were admitted to the well-baby nursery where they were cared for in Gordon-Armstrong incubators for the first $12 \mathrm{~h}$ after birth, then in open bassinets. They were first fed at 6-8 h of age with sterile water and subsequently with infant formula every $4 \mathrm{~h}$. The well preterm neonates were admitted to the Special Care Nursery where they were cared for in servo-controlled incubators for at least the first 3 days of life; they were initially fed at $6-8 \mathrm{~h}$ of age with sterile water, and infant formula every $3 \mathrm{~h}$ thereafter. The sick or high-risk infants were admitted to the intensive care nursery where they were cared for in open servo-controlled radiant warmers during the acute phase of their disease. There was no change in the routine care of these infants for the purposes of this study. Although fluid therapy was at the discretion of the attending physician, it was similar among infants, averaging $70-80 \mathrm{ml} / \mathrm{kg}$. day for the first $72 \mathrm{~h}$ and consisting of $10 \%$ dextrose and water for the initial 12-24 $\mathrm{h}$ and $10 \%$ dextrose with 0.25 isotonic saline thereafter. Fluid therapy, oral and/or parenteral, was gradually increased, reaching values of $\sim 120 \mathrm{ml} / \mathrm{kg}$. day by day 7 of life.

Urine, voided spontaneously into either plastic bags or tubes, was collected as soon after birth as possible and then continuously at 3-h intervals for 2-4 days. In no case in either the sick or highrisk infants was there evidence of renal failure or oliguria, i.e. a urine output of $<0.5 \mathrm{ml} / \mathrm{kg} \cdot \mathrm{h}$. Urine volume was measured and specimens were handled as described below.

Urinary AVP was measured by radioimmunoassay using rabbit antiserum R-71. The production of antiserum R-71 and its use in the measurement of adult human urinary AVP were described earlier by Skowsky et al. (18) and Tausch et al. (19), respectively. In the present investigation, urine was collected during a 3-h period from human newborns, the volume was measured, and aliquots of $1-\mathrm{ml}$ were frozen $\left(-20^{\circ} \mathrm{C}\right)$. Within 2 months, the samples were thawed, acidified ( $\mathrm{pH} 2$ to 3 ) by the addition of $0.1 \mathrm{ml}$ of $1 \mathrm{~N} \mathrm{HCl}$ and AVP was extracted from the urine by the methods of Crofton et al. (20) and Tausch et al. (19), using $C_{18}$ Sep Pak cartridges (Waters Associates, Inc., Milford, MA). The extract was evaporated to dryness, and the residue was suspended in $400 \mu \mathrm{l}$ of assay buffer (2). The efficacy of this extraction process was evaluated in the following manner. USP bovine posterior pituitary extract (supplied by Dr. Aubrey S. Autchorn, United States Pharmacopeia, Rockville, MD) was added to a fresh pool of human newborn urine and extracted. The recovery of AVP was $87.1 \pm 5.5 \%(\vec{x} \pm \mathrm{SE}, n=10)$.
Table 2. Measurement and validation of AVP in neonatal urine $($ mean $\pm S E)$

\begin{tabular}{cc}
\hline Method of treatment & AVP concentration $(\mu \mathrm{U} / \mathrm{ml})$ \\
\hline A & $5.8 \pm 0.17(4)^{*}$ \\
B & $6.5 \pm 0.44(4)$ \\
C & $6.1 \pm 0.34(3)$ \\
D & $8.1 \pm 0.29(4)$ \\
E & $12.7 \pm 0.56(3)$ \\
F & $9.6 \pm 0.10(3)$
\end{tabular}

* Number of determinations is shown in parentheses.

The stability of urinary AVP was evaluated under several conditions. Urines from two newborn infants at term were combined, and aliquots of the pooled urine were treated according to one of the following paradigms: (A) immediately acidified and extracted; (B) immediately frozen and after 2 months of storage at $-20^{\circ} \mathrm{C}$ acidified and extracted; (C) immediately cooled and after 2 months of storage at $4^{\circ} \mathrm{C}$ acidified and extracted; (D) immediately acidified, frozen, and after 2 months of storage at $-20^{\circ} \mathrm{C}$ extracted; (E) immediately acidified, frozen, and after 4 months of storage at $-20^{\circ} \mathrm{C}$ extracted; or $(\mathrm{F})$ immediately acidified, cooled, and extracted after 2 months of storage at $4^{\circ} \mathrm{C}$. The results of this experiment are shown in Table 2. The results obtained with methods $\mathrm{A}, \mathrm{B}$, and $\mathrm{C}$ did not differ significantly $(p>0.05)$ from each other. However, the mean concentrations of AVP in urine treated by methods $\mathrm{D}, \mathrm{E}$, and $\mathrm{F}$, i.e. acidified before storage, were significantly higher $(p<0.05)$ than those in urine treated by methods $\mathrm{A}, \mathrm{B}$, or $\mathrm{C}$. Moreover, the longer the storage period, the greater the discrepancy. It is possible that this apparent increase in the concentration of AVP in urine is a reflection of the dissociation of immunoreactive AVP or its metabolites from a carrier protein. In the present study, the method of treatment of newborn urine was similar to that followed in method $\mathrm{B}$, i.e. the urine was stored at $-20^{\circ} \mathrm{C}$ and within 2 months was acidified and extracted.

Creatinine was measured by Auto-Analyzer (21) and osmolality by freezing-point depression (Osmette A, Precision Systems, Inc., Sudbury, MA).

Mean values for urinary AVP excretion $(\mu \mathrm{U} / \mathrm{mg} \mathrm{Cr}$ ) were determined for the sequential time periods $0-6,7-12,13-18$, 19-24, 25-36, and 37-48 h after birth and for subsequent $12-\mathrm{h}$ intervals in those infants studied for more than $48 \mathrm{~h}$. Statistical analysis of data was performed using one-way and where indicated, two-way analysis of variance with repeated measures, linear regressions, and either Welch's approximation to the $t$ test or Student's $t$ test when study and control data were compared. The level of significance was considered to be $p<0.05$.

\section{RESULTS}

The patterns of urinary AVP excretion over time were not different when analyzed as either $\mu \mathrm{U} / \mathrm{ml}$ or $\mu \mathrm{U} / \mathrm{mg} \mathrm{Cr}$; thus, we 
have chosen to present all data as $\mu \mathrm{U}$ of $\mathrm{AVP} / \mathrm{mg} \mathrm{Cr}$. The mean values for the sequential urinary excretion of AVP $(\mu \mathrm{U}$ of AVP/ $\mathrm{mg} \mathrm{Cr}$ ) during the first $48 \mathrm{~h}$ of life in control infants (group 1) and for each group of study infants are presented in Table 3. Of the control groups, preterm infants tended to have higher mean values for urinary AVP excretion throughout the study period; these differences. however, were significant only at 7-12 and 37$48 \mathrm{~h}(p<0.05)$. The pattern of urinary excretion in the control groups was similar, decreasing during the first $12 \mathrm{~h}$ after birth to relatively lower values thereafter.

Seventeen infants with meconium stained amniotic fuid (groups 2 and 3 ) and more than $36 \mathrm{wk}$ of gestation were studied. Eleven infants (group 2) had evidence of significant intrapartum asphyxia (Table 1) with Apgar scores at 1 and 5 min significantly lower than well term infants $(p<0.001)$; five were delivered by cesarean section because of fetal distress and subsequently had meconium aspiration syndrome. Although the pattern of AVP excretion in group 2 was one of gradually decreasing levels, the mean urinary AVP excretion remained $\geq 89 \mu \mathrm{U} / \mathrm{mg} \mathrm{Cr}$ for the first $24 \mathrm{~h}$ after birth; values were significantly greater than normal term infants at $13-18$ and $37-48 \mathrm{~h}$. The highest urinary AVP value obtained in this group, $598 \mu \mathrm{U} / \mathrm{mg} \mathrm{Cr}$, was in an infant with Apgar scores of 2,4, and 5 at 1,5, and $10 \mathrm{~min}$, respectively, severe meconium aspiration syndrome, and evidence of pulmonary hypcrtension. In contrast, infants in group 3 did not have evidence of intrapartum asphyxia (Table 1) and had lower levels of mean urinary AVP initially and throughout the study period. None of these infants required mechanical ventilation, whereas six of the 11 asphyxiated infants in group 2 did.

Group 4 is comprised of 13 preterm infants who had significant birth asphyxia and whose $\Lambda$ pgar scores were significantly lower than well preterm infants at 1 and $5 \min (p<0.001)$. None of these infants developed either clinical or radiographic evidence of HMD: 11 required mechanical ventilation because of birth asphyxia, cight for less than $48 \mathrm{~h}$. There was no evidence of meconium-stained amniotic fluid. As illustrated in Figure 1 and Table 2, the initial value for mean urinary AVP was significantly greater than that observed in well preterm infants, but not different from that found in asphyxiated term infants (group 2). As in well preterm infants, urinary AVP excretion fell rapidly within $12 \mathrm{~h}$ after birth and remained relatively stable thereafter: nevertheless, mean values were higher than those observed in well infants, differences that were significant at $0-6$ and $19-36 \mathrm{~h}$ of age.

In vicw of the apparent relationship between perinatal asphyxia and increased urinary AVP excretion, we examined the relationship between the $1 \mathrm{~min}$ Apgar score (which generally does not reflect resuscitative efforts) and initial urinary AVP values in infants included in groups $1-4$. A significant negative correlation was obtained. The equation describing this relationship is: $\mathrm{AVP}_{\mathrm{I},\left(x_{i}\right.}=5.087+(-0.116)$ Apgar score, $r=-0.46, p=0.001$. It is noteworthy that the strongest correlation was obtained when term infants in groups $1-3$ were analyzed alone (Fig. 2): AVP $P_{1 . O ;}$ $=5.306+(-0.156)$ Apgar score, $r=-0.60, p=0.003$.

Group 5 consists of 16 preterm infants who developed HMD and survived. Their $1 \mathrm{~min}$ Apgar scores were higher $(p<0.001)$ than those for infants in group 4 . All of these infants required assisted ventilation for 45 to $100 \mathrm{~h}$. Although their mean urinary AVP levels were somewhat greater than those of well preterm infants at all time periods, differences were statistically significant only at 7-12 and $37-48 \mathrm{~h}$ of age. Of note, the pattern of urinary AVP excretion was similar to that of the well neonates. The rise in urinary AVP observed at $37-48 \mathrm{~h}$ is likely reflective of the development of pneumothorax at this time in two infants (see below).

In the infants with HMD who did not survive (group 6), both the mean birth weight and gestational age were significantly less than that of infants in groups 4 and 5 and the control preterm infants. $p<0.05$. Four infants developed PV-IVH and two had hypoxic-ischemic encephalopathy, the latter diagnosed at autopsy. Furthermore, these infants had a high incidence of prenatal complications, such as severe maternal hypertension. Thus, multiple variables might have affected their excretion of AVP initially (2) and subsequently during the neonatal period. In contrast to the gradual fall in urinary AVP excretion seen in the other study groups, a progressive rise in mean urinary AVP excretion appears to occur soon after birth and values are greater than those for control preterm infants from 19 to $48 \mathrm{~h}$. Never-

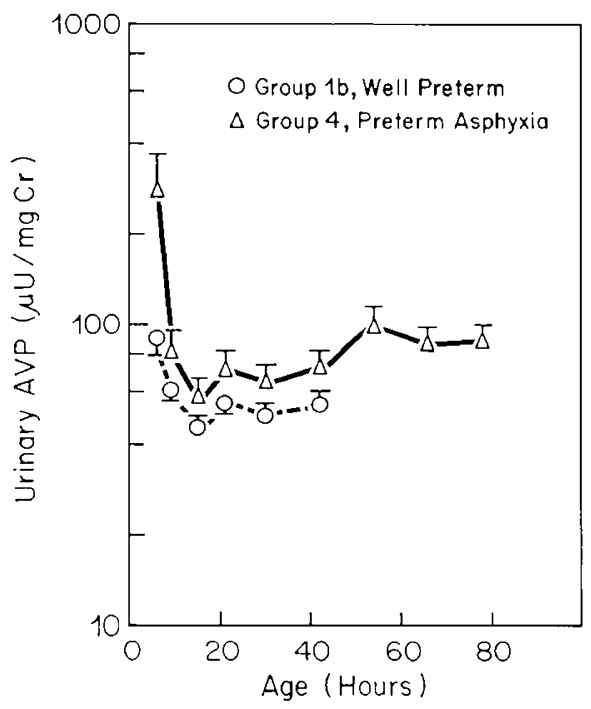

Fig. 1. The pattern of urinary AVP excretion over the first 4 days of life in preterm infants with asphyxia and without clinical hyaline membrane disease $(n=13)$ as compared to well preterm infants $(n=13)$. Means \pm SE are presented.

\begin{tabular}{|c|c|c|c|c|c|c|c|c|}
\hline & \multirow[b]{2}{*}{ Group } & \multirow[b]{2}{*}{$n$} & \multicolumn{6}{|c|}{ Age $(\mathrm{h})$} \\
\hline & & & $0-6$ & $7-12$ & $13-18$ & $19-24$ & $25-36$ & $37-48$ \\
\hline \multicolumn{9}{|c|}{ 1. Control } \\
\hline & a. Term & 12 & $52.5 \pm 35.7$ & $43.1 \pm 3.7$ & $40.8 \pm 5.3$ & $42.7 \pm 8.3$ & $42.9 \pm 9.0$ & $27.6 \pm 1.5$ \\
\hline & b. Preterm & 13 & $91.6 \pm 1.3 .3$ & $64.4 \pm 6.5$ & $46.0 \pm 3.9$ & $55.2 \pm 3.8$ & $62.6 \pm 12.5$ & $56.3 \pm 6.1$ \\
\hline 2. & MSAF/asphyxia & 11 & $217 \pm 127$ & $143 \pm 57$ & $205 \pm 78+$ & $89 \pm 27$ & $48 \pm 6.3$ & $45 \pm 6.0 \div$ \\
\hline 3. & MSAF/no asphyxia & 6 & $87 \pm 38$ & $82 \pm 22$ & $39 \pm 8.1$ & $30 \pm 3.4$ & $19 \pm 2.8+$ & $18 \pm 2.7 \ddagger$ \\
\hline 4. & Preterm/asphyia w/o HMD & 13 & $288 \pm 84 \div$ & $81 \pm 16$ & $57 \pm 10$ & $73 \pm 9.1 \dagger$ & $65 \pm 8.8+$ & $72 \pm 10$ \\
\hline 5 & Preterm $/ \mathrm{HMI} / \mathrm{S}$ & 16 & $124 \pm 23$ & $219 \pm 90+$ & $77 \pm 21$ & $85 \pm 27$ & $68 \pm 6.9$ & $109 \pm 16 \ddagger$ \\
\hline 6. & Preterm/HMI)/NS & 7 & & $99 \pm 46$ & $451 \pm 388$ & $1540 \pm 1023 \dagger$ & $929 \pm 700+$ & $146 \pm 42 \ddagger$ \\
\hline
\end{tabular}

* Abbreviations are as in Table 1.

$+0.05<p<0.10$ when compared to the appropriate control infants in group 1.

fi $p<0.05$. 


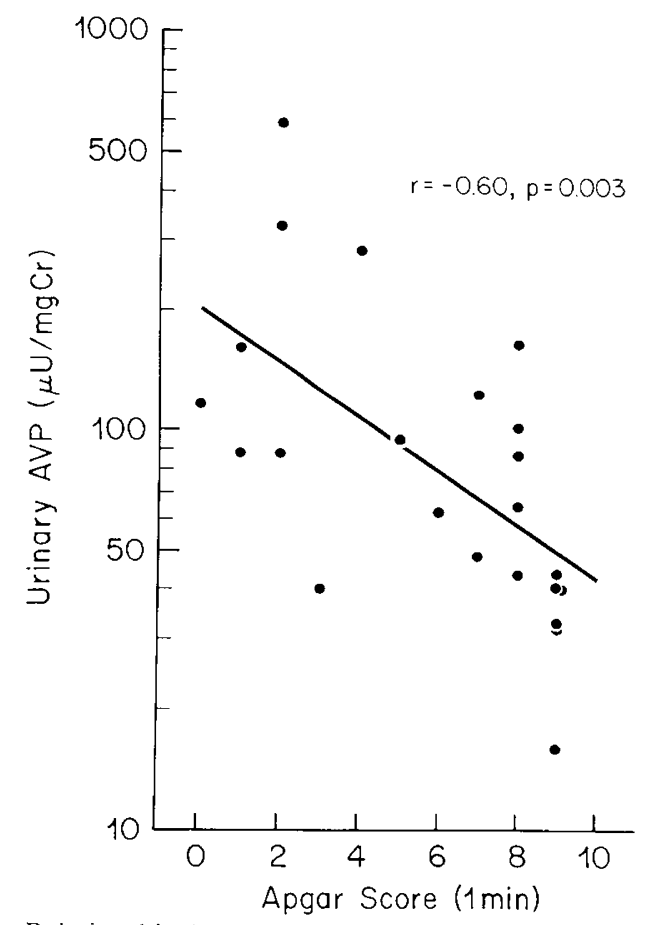

Fig. 2. Relationship between urinary AVP excretion (natural logarithm) and the 1-min Apgar score in term infants in groups 1-3.

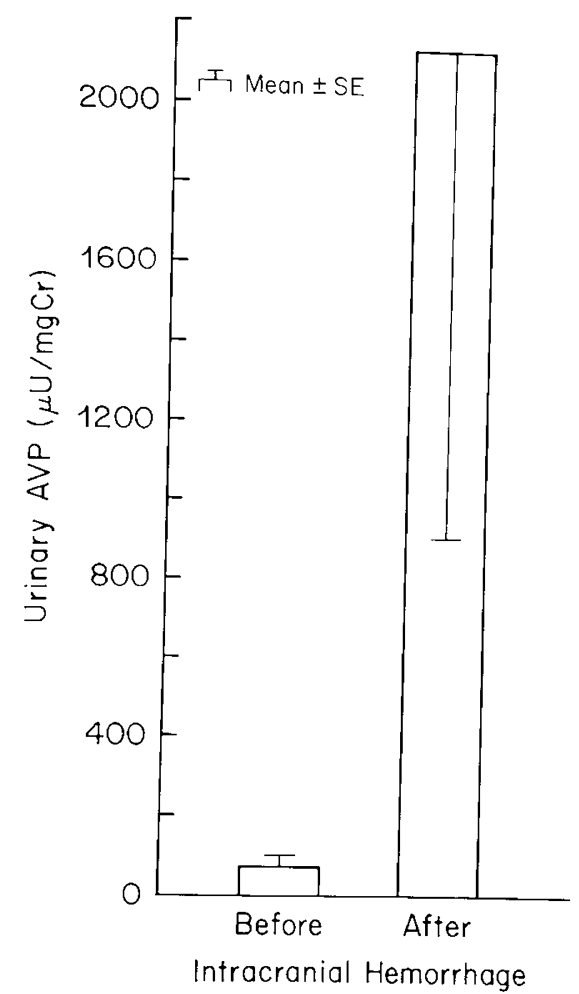

Fig. 3. Urinary excretion of AVP in four preterm infants before and after periventricular-intraventricular hemorrhage.

theless, oliguria was not observed. In four infants urine samples were obtained both before and after the diagnosis of PV-IVH; as seen in Figure 3, a marked rise in urinary AVP occurred after PV-IVH, levels increasing 2- to 75-fold and remaining elevated for some time thereafter. Although values rose in all four infants, statistical significance was not achieved because of the small study group. Also of interest was the pattern of urinary AVP observed in the two infants with severe hypoxic-ischemic en- cephalopathy diagnosed at autopsy. They had relatively low levels of urinary AVP for the first $40 \mathrm{~h}$ after birth $(<90 \mu \mathrm{U} / \mathrm{mg} \mathrm{Cr})$ followed by a subsequent rise, attaining levels of $>150 \mu \mathrm{U} / \mathrm{mg}$ $\mathrm{Cr}$ after $60 \mathrm{~h}$ of age.

In four infants urine samples were obtained in temporal relationship to the occurrence of pneumothorax (Fig. 4). As expected from the report of Stern et al. (9), mean urinary AVP excretion rose with the occurrence of pneumothorax, reaching a maximum value of $334 \mu \mathrm{U} / \mathrm{mg} \mathrm{Cr}$ at the time of pneumothorax and decreasing to $60 \mu \mathrm{U} / \mathrm{mg} \mathrm{Cr}$ within $6 \mathrm{~h}$ following evacuation of the air.

Because of the elevated levels of urinary AVP observed in the sick infants studied and the marked absence of clinical or laboratory evidence of the syndrome of inappropriate antidiuretic hormone, we examined the relationship between urinary osmolality and urinary AVP excretion. Extremely weak linear correlations were observed in groups $2(r=0.41, p<0.001)$ and $5(r$ $=0.37, p<0.001$ ), and no significant correlations were found in either well term or preterm infants or infants in groups 3,4 , or 6. We did observe in all groups that a nonlinear relationship existed between urinary AVP and osmolality, i.e. urinary osmolality rose to a maximum of $\sim 400 \mathrm{mosmol} / \mathrm{kg}$ at AVP values $<200 \mu \mathrm{U} / \mathrm{mg} \mathrm{Cr}$ and plateaued thereafter despite increases in urinary AVP to values greater than $600 \mu \mathrm{U} / \mathrm{mg} \mathrm{Cr}$. A typical relationship is illustrated in Figure 5 with data obtained from infants in group 2.

\section{DISCUSSION}

In these studies we provide descriptive and comparative data of the patterns of urinary AVP excretion in neonates with and without perinatal complications. We have demonstrated that although most of these infants have a pattern of decreasing AVP excretion following birth, levels of urinary AVP depend on the presence or absence of intrapartum or neonatal complications. We chose to examine selected groups of infants based on our previous observations of human umbilical cord plasma AVP concentrations (2) and studies of the fetal sheep (22), and sought to describe in these infants their urinary excretion of this important peptide hormone as a reflection of plasma concentrations.

Part of the problem in ascertaining the role of AVP in the neonatal period has been the difficulty in obtaining multiple blood samples of sufficient volume $(>1.0 \mathrm{ml})$ over prolonged periods of time. The renal handling of AVP has been studied extensively, and there is considerable evidence that glomerular filtration is the primary source of urinary AVP in the adult (23)

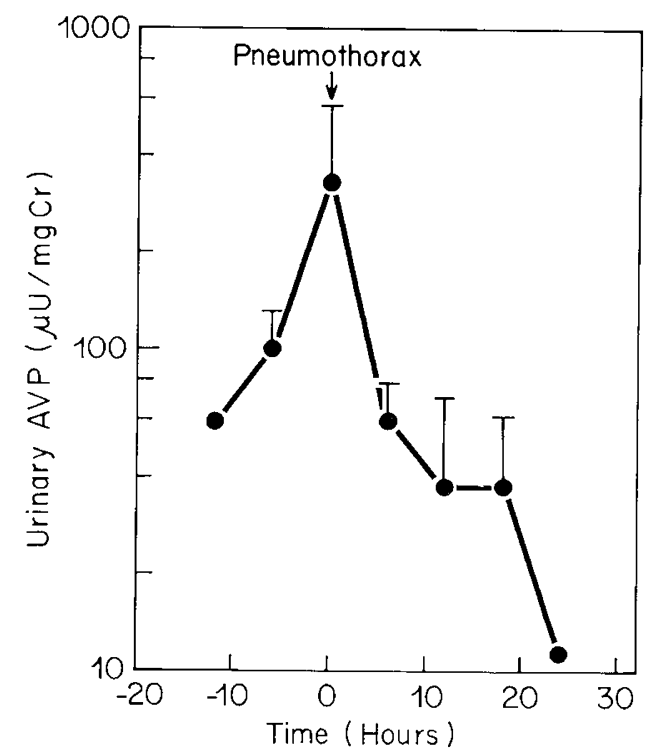

Fig. 4. The pattern of urinary AVP excretion in infants with pneumothorax $(n=4)$. Means \pm SE are presented. 


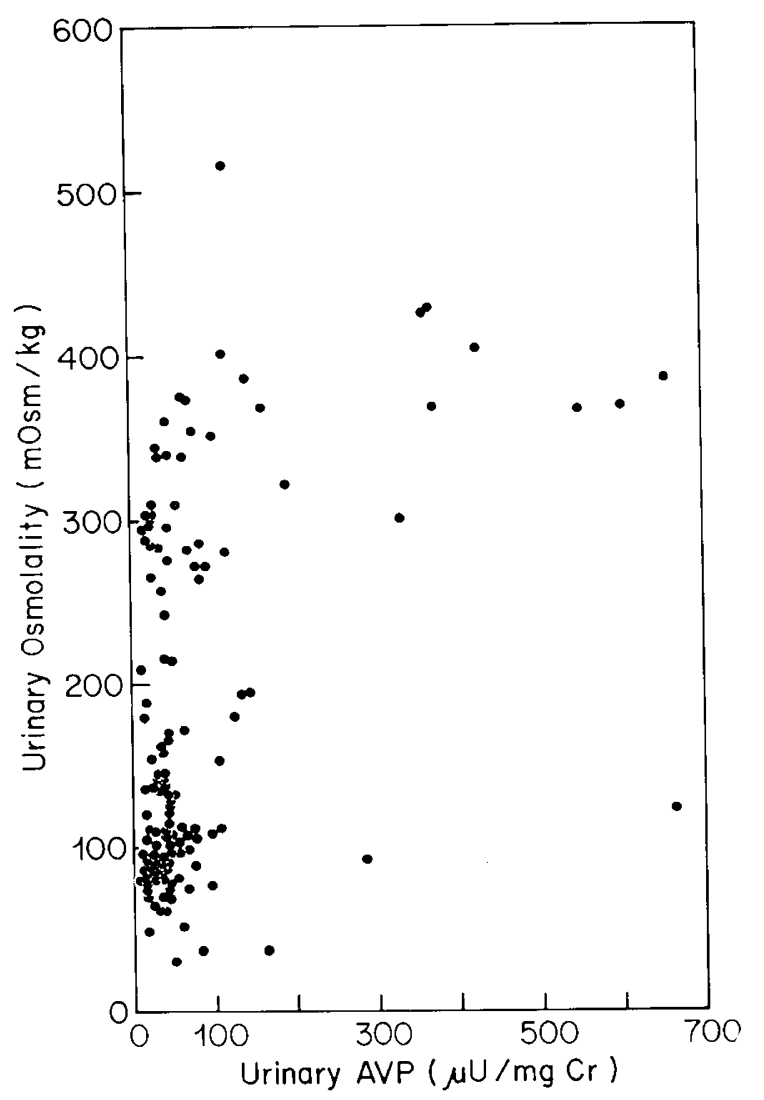

Fig. 5. The relationship between urinary osmolality and urinary AVP concentration $(\mu \mathrm{U} / \mathrm{mg} \mathrm{Cr})$ in term infants with asphyxia and meconium stained fluid (group 2).

and normal term infant beyond the second day (24). Furthermore, it has been shown that AVP is neither secreted nor destroyed by the renal tubules (25) and that AVP in adult urine is stable over long periods of time (19). In this report we present data regarding the stability of AVP in the urine of neonates and how it might be collected, stored, and assayed. Thus, it appears that measurement of urinary AVP excretion provides a good index of plasma AVP concentrations as long as hydration and renal function are normal. Additional support for this is obtained from recent studies in which urinary AVP excretion has been reported to vary directly with plasma AVP concentrations in adult dogs (13), fetal and neonatal sheep (14), and human adults and neonates $(5,9,15)$. Finally, we have reported (26) that elevations of plasma AVP in fetal sheep are reflected by subsequent rises in amniotic fluid AVP concentrations, which should reflect urinary excretion of this hormone.

The initial pattern of urinary AVP excretion in the well infant is probably reflective of AVP hypersecretion that occurs during parturition. Alexander et al. (27) suggested that AVP might be important in the onset of parturition. However, in more detailed studies of corticotrophin-induced parurition in sheep, Stark et al. (28) demonstrated that labor actually began prior to the rise in fetal plasma AVP concentrations. They concluded that the increase in fetal plasma AVP represented a response to the relative hypoxemia and acidosis normally associated with labor. That this occurs in the human is supported by higher umbilical cord plasma concentrations of AVP after vaginal delivery as compared to cesarean delivery with or without labor (2). Thus, it follows that if plasma AVP is cleared in part by means of renal excretion and AVP secretion decreases following birth $(3,5)$, a gradual decline in urinary AVP levels will occur in well term and preterm infants over the first 24-48 h of life. Furthermore, a similar pattern of AVP excretion would be expected in infants delivered of complicated pregnancies, barring neonatal compli- cations that might result in increased AVP secretion, e.g. hypoxia or hemorrhage; however, initial values might be higher when antepartum or intrapartum complications result in additional fetal stresses (2).

In this study we elected to examine term infants with meconium-stained amniotic fluid with and without evidence of perinatal asphyxia because of our observations that umbilical cord plasma concentrations of AVP were highest in infants with meconium stained amniotic fluid (2) and in asphyxiated fetal sheep with meconium expulsion (22). As might have been predicted, the highest levels of urinary AVP immediately after birth, 0-6 hours, were among infants with both asphyxia and meconium-stained amniotic fluid. Although there is general agreement that fetal asphyxia results in the hypersecretion of AVP, little is known about its relationship to meconium release. It has been suggested that fetal asphyxia and/or hypoxia are associated with constriction of the mesenteric vessels, an increase in gastrointestinal peristalsis, relaxation of the anal sphincter, and release of meconium into the amniotic sac. The mechanism(s) responsible, however, is unclear. AVP is a potent constrictor of the mesenteric vascular bed and stimulant of large bowel peristalsis $(29,30)$. Furthermore, in contrast to the more transient effects of catecholamines, those of AVP are persistent and tachyphylaxis is unusual (31). Thus, it is possible that fetal hypersecretion of AVP during asphyxia may be important in the mechanism of meconium expulsion. Support for this has been obtained in studies of near-term fetal sheep, in whom high rates of vasopressin infusion resulted in meconium release while arterial $\mathrm{PO}_{2}, \mathrm{PCO}_{2}$, and $\mathrm{pH}$ remained within normal ranges (26). Additional studies in fetal sheep are underway to further validate this relationship.

Although mean levels of urinary AVP fell after birth in infants with meconium stained amniotic fluid (groups 2 and 3), they remained elevated in those with intrapartum asphyxia when compared to infants without asphyxia and well term infants. This may reflect the development of meconium aspiration syndrome with relative hypoxemia and hypercapnia in five infants and/or the need for mechanical ventilation in $55 \%$ of this group $(32,33)$. It was not unusual to find a fall in urinary AVP concomitant with an improvement in lung disease in individual cases; but there are presently too few cases to make any further comments.

As in asphyxiated term infants, initial urinary AVP concentrations in asphyxiated preterm infants (group 4) were greater than those observed in respective control infants (group 1b). Moreover, a significant negative correlation was found between the 1 min Apgar score and the initial level of urinary AVP in groups $1-4$. Therefore, it is likely that initial values for urinary AVP are reflective, as noted earlier, of intrapartum stress and asphyxia, and that the preterm infant, like the term infant, is capable of eliciting significant AVP release. The higher mean values found throughout the study period in this group as compared to controls could reflect, as noted earlier, the need for mechanical ventilation in $85 \%$ of these infants. The absence of meconium stained amniotic fluid is not surprising since infants less than $34 \mathrm{wk}$ of gestation rarely pass meconium in utero (34). This could represent either a developmental phenomenon, i.e. decreased responsiveness to AVP, or the absence of meconium in the distal colon of preterm infants.

Hypersecretion of AVP in the fetus has been considered to result mainly in cardiovascular as compared to renal alterations $(1,29)$; however, some renal effects are likely to occur $(8)$. We found that urinary AVP levels were not linearly related with a rise in urinary osmolality; but rather, urine osmolality rose to a maximum of $\sim 400 \mathrm{mosmol} / \mathrm{kg}$ and despite further increases in urinary AVP concentration did not rise further (Fig. 4). This observation is similar to that of Robillard and Weitzman (1), who compared plasma AVP concentration with urinary osmolality in unstressed fetal sheep, and Rees et al. (5), who compared urine osmolality with AVP excretion in a single infant between 7 and 19 days of age. This relative refractoriness of the neonatal kidney to the antidiuretic effects of AVP may be reflective of the 
presence of an AVP antagonist at the level of the renal collecting duct, e.g. prostaglandin $\mathrm{E}_{2}$ (35). Such an antagonist might explain the uncommon occurrence of the syndrome of inappropriate antidiuretic hormone in sick neonates despite high levels of AVP secretion.

Increased urinary (7) and plasma (4) concentrations of AVP also have been reported in infants with HMD. We too found increased urinary excretion of AVP in survivors (group 5) and nonsurvivors (group 6) with HMD. In the survivors, all of whom required mechanical ventilation, the pattern of AVP excretion was similar to that of well preterm infants; although not significantly different, mean values were somewhat higher for each time interval. As noted earlier, the increased release of AVP may reflect the use of mechanical ventilation and the role of intrathoracic baroreceptors $(32,33)$, which in turn may reflect changes in cardiac output and its distribution during positive pressure ventilation, a phenomenon demonstrated to occur with continuous positive airway pressure (36). It has been suggested that increased AVP release or a failure of the normal fall in AVP to occur after birth may affect the course of HMD through its effects on lung water (37). This, however, remains controversial.

The marked increases in urinary AVP excretion observed in infants with PV-IVH is noteworthy and consistent with the observations of Rees et al. (6). Acute increases in intracranial pressure have been reported to result in increased plasma AVP concentrations in monkeys (38). Furthermore, it has been suggested that irritation of the supraoptic or paraventricular nuclei or the hypophyseal tract (events thought to occur with PV-IVH) results in AVP release and development of the syndrome of inappropriate antidiuretic hormone (39). From the pattern of AVP excretion found in the present study, it is likely that the rise in AVP excretion seen in association with PV-IVH is reflective of the occurrence of the hemorrhage. Since AVP is a potent vasoconstrictor (30), the metabolic acidosis associated with PVIVH may reflect decreased peripheral perfusion and the relative tissue hypoxia that might occur.

Although others (7) have observed a rise in AVP secretion with hypoxic-ischemic encephalopathy, we were impressed by the persistent and apparent progressive increase in AVP excretion found in this group. It is unclear whether the rise in AVP excretion is associated with a response to the disease process or represents a pathologic role for AVP.

In the present study we have shown that infants with a variety of perinatal problems may have increases in the urinary excretion of AVP. The extent to which AVP is a marker for these conditions as opposed to being a critical variable in their pathogenesis is unclear in some instances. Furthermore, exactly how this hormone fits into the complicated pathophysiologic responses to either fetal or neonatal "stress" also remains unclear. Nevertheless, it must be considered that in some instances AVP may function as more than a nonspecific "stress hormone," i.e. it may be an important contributor to the final pathologic state.

Acknowledgments. The authors acknowledge the excellent secretarial assistance of Roz Thomas and Marilyn Dixon in the preparation of the manuscript and the assistance of the nursing staff, Special Care Nursery, Parkland Memorial Hospital.

The rabbit antiserum R-71 was a gift from the late Dr. R E. Weitzman.

\section{REFERENCES}

1. Robillard JE, Weitzman RE 1980 Developmental aspects of the fetal renal response to exogenous arginine vasopressin. Am J Physiol 238:F407-F444

2. DeVane GW. Porter JC 1980 An apparent stress-induced release of arginine vasopressin by human neonates. J Clin Endocrinol Metab 51:1412-1416

3. Hadecd AJ, Leake RD. Weit $/$ man RE. Fisher DA 1979 Possible mechanisms of high blood levels of vasopressin during the neonatal period. J Pediatr 94:805-808

4. Rees L. Forsling ML, Brook CGD 1980 Vasopressin concentrations in the neonatal period. Clin Endocrinol 12:357-362

5. Rees L, Brook CGD. Forsling ML 1983 Continuous urine collection in the study of vasopressin in the newborn. Horm Res 17:134-140
6. Rees L, Brook CGD, Shaw JCL, Forsling ML 1984 Hyponatremia in the first week of life in preterm infants: Part I. Arginine vasopressin secretion. Arch Dis Child 59:414-422

7. Kaplan SL, Feigin RD 1978 Inappropriate secretion of antidiuretic hormone complicating neonatal hypoxic-ischemic encephalopathy. J Pediatr 92:431433

8. Stern P, LaRochelle FT, Little GA 1979 Role of vasopressin in water imbalance of the sick newborn. Kidncy Int 16:956A

9. Stern P, LaRochelle FT, Little GA 1981 Vasopressin and pneumothorax in the neonate. Pediatrics 68:499-503

10. Kaplan SL, Feigin RD 1980 Syndromes of inappropriate secretion of antidiuretic hormone in children. Adv Pediatr 27:247-274

11. Harvey N, Jones JJ, Lee J 1967 The renal clearance and plasma binding of vasopressin in the dog. J Endocrinol 38:163-171

12. Share L, Shade RE, Rabkin R 1977 Studies of the metabolism of vasopressin, with emphasis on the role of the kidney. In: Neurohypophysis International Conference, Karger, Basel, pp 189-200

13. Matsui K, Share L, Wang BC, Crofton JT, Brooks DP 1983 Effect of changes in steady state plasma vasopressin levels on renal and urinary vasopressin clearance in the dog. Endocrinology 112:2107-2113

14. Daniel SS, Stark RI, Husain MK. Sanocka UM, James LS 1982 Excretion of vasopressin in the hypoxic lamb: comparison between fetus and newborn. Pediatr Res 18:227-231

15. Stern P, LaRochelle FT 1982 Similar relationship betwen plasma and urinary vasopressin (VP) in infants and adults. Pediatr Res 16:329A

16. Weitzman RE, Fisher DA, DiStefano JJ, Bennett CM 1977 Episodic secretion of arginine vasopressin. Am J Physiol 233:E32-E36

17. Farrell PM, Avery ME 1975 Hyaline membrane disease. Am Rev Respir Dis 111:657-688

18. Skowsky WR, Rosenbloom AA, Fisher DA 1974 Radioimmunoassay measurement of arginine vasopressin in serum: development and application. $J$ Clin Endocrinol Metab 38:278-287

19. Tausch A, Stigner H, Leake RD, Artman HG, Fisher DA 1983 Radioimmunoassay of arginine vasopressin in urine: development and application. J Clin Endocrinol Metab 57:777-781

20. Crofton JT, Share L, Wang BC, Shade RE 1980 Pressor responses to vasopres$\sin$ in the rat with DOC-salt hypertension. Hypertension 2:424-431

21. Arant BS Jr 1978 Developmental patterns of renal functional maturation compared in the human neonate. J Pediatr 92:705-712

22. DeVane GW, Naden RP, Porter JC. Rosenfeld CR 1982 Mechanism of arginine vasopressin release in the sheep fetus. Pediatr Res 16:504-507

23. Baumann G, Dingman JF. 1976. Distribution, blood transport and degradation of antidiuretic hormone in man. J Clin Invest 57:1109-1116

24. Godard C, Geering JM, Geering K, Vallottan MB 1979 Plasma renin activity related to sodium balance, renal function, and urinary vasopressin in the newborn infant. Pediatr Res 13:742-745

25. Lindheimer MD, Reinharz A, Grandchamp A, Vallottan MB 1980 Fate of vasopressin perfused into nephrons of Wistar and Brattleboro (diabetes insipidus) rats. Clin Sci 58:139-144

26. Wiriyathian S, Porter JC, Naden RP, Rosenfeld CR 1983 Cardiovascular effects and clearance of cxogenous arginine vasopressin in the fetal lamb. Am J Physiol 245:E24-E31

27. Alexander DP, Bashore RA, Britton HG, Forsling ML 1974 Maternal and fetal arginine vasopressin in the chronically catheterized sheep. Biol Neonate 25:242-248

28. Stark RI, Daniel SS, Husain MK, Milliez J, Morishima HO, James LS, Van de Wiele R 1981 Release of vasopressin by the fetal lamb during premature parturition induced with corticotrophin. Pediatr Res 16:1261-1265

29. Hays RM. 1980. Agents affecting the renal conservation of water. In: Goodman LS, Gilman AG (eds): The Pharmacological Basis of Therapeutics. MacMillan and Co.. New York, pp 916-928

30. Iwamoto HS, Rudolph AM, Keil LC, Heymann MA 1979 Hemodynamic responses of the shecp fetus to vasopressin infusion. Circ Res 44:430-436

31. Dresel P, Wallentin I 1966 Effects of sympathetic vasoconstrictor fibres, noradrenaline and vasopressin on the intestinal vascular resistance during constant blood flow or blood pressure. Acta Physiol Scand 66:427-436

32. Hemmer M, Viquerat CE, Suter PM, Vallottan MB 1980 Urinary antidiuretic hormone excretion during mechanical ventilation and meaning in man. Anesthesiology 52:395-400

33. Kumar A, Pontoppidan H, Baratz RA, Laver MB 1974 Inappropriate response to increased plasma ADH during mechanical ventilation in acute respiratory failure. Anesthesiology 40:215-221

34. Matthews TG, Warshaw JB 1979 Relevance of the gestational age distribution of meconium passage in utero. Pediatrics 64:30-31

35. Joppich R. Haberle DA. Weber PC 1981 Studies in the immaturity of the ADH-dependent CAMP system in conscious newborn piglets-possible impairing effects of renal prostaglandins. Pediatr Res 15:278-281

36. Furzan JA, Gabriele G, Whecler JM. Fixler DE, Rosenfeld Cr 1981 Regional blood flows in newborn lambs during endotracheal continuous airway pressure and continuous negative pressure breathing. Pediatr Res 15:874-878

37. Perks AM, Cassin S 1982 The effects of arginine vasopressin and other factors on the production of lung fluid in fetal goats. Chest 81: (suppl) 63-65

38. Gaufin L, Skowsky WR, Goodman SJ 1977 Relcase of antidiuretic hormone during mass-induced elevation of intracranial pressure. J Neurosurg 46:627637

39. Olson DR, Buchan GC, Porter GA 1969 The syndrome of inappropriate antidiuretic hormone secretion; an unusual case. Arch Intern Med 124:741747 